\title{
Responsabilidade socioambiental de uma organização sem fins econômicos para o desenvolvimento regional
}

\author{
Evanilde Gollo Cordazzo ${ }^{1}$ \\ Edaiane Fátima Comonelli ${ }^{2}$ \\ Sady Mazzioni ${ }^{3}$ \\ Giana de Vargas Mores ${ }^{4}$
}

\begin{abstract}
Resumo
O estudo objetivou analisar as práticas de responsabilidade socioambiental adotadas pelo Instituto Goio-En para o desenvolvimento regional no seu âmbito de atuação. A pesquisa descritiva, com abordagem qualitativa, foi realizada por meio de entrevistas com gestores e pela análise de conteúdo documental, avaliando as práticas de responsabilidade socioambiental. Os principais achados indicam que o Instituto Goio-En atua de forma social e ambientalmente responsável, com foco na produção de alevinos para o repovoamento do rio Uruguai e o lago da barragem Foz do Chapecó. As atividades do Instituto norteiam-se por princípios éticos de governança e com observância à legislação, assegurando uma gestão transparente e participativa. Sua atuação visa ao desenvolvimento regional com foco na sustentabilidade, estimulando práticas de preservação e conservação do ecossistema e dos recursos naturais. A fim de garantir a própria sustentabilidade, o Instituto busca estratégias para a captação de recursos, por meio de parcerias e convênios, ou da comercialização de alevinos.
\end{abstract}

Palavras-chave: Responsabilidade socioambiental. Organização sem fins lucrativos. Desenvolvimento regional. Sustentabilidade.

\begin{abstract}
The study aimed to analyze the socioenvironmental responsibility practices adopted by the Goio-En Institute in regional development. Descriptive research with a qualitative approach was conducted through interviews with managers, content analysis, and documentary analysis to evaluate socioenvironmental responsibility practices of the specific organization. The main findings indicate that the Goio-En Institute operates in a socially and environmentally responsible way, focusing on the production of fingerlings for the repopulation of the Uruguay River and lake of the Foz do Chapecó dam. The activities of the institute are governed by ethical principles and comply with legislation, ensuring transparent and participatory management. The Goio-En Institute aims to achieve regional development with a focus on sustainability, ensuring the preservation and conservation of the ecosystem and its natural resources. To guarantee its own sustainability, the institute raises funds through partnerships and agreements as well as through the marketing of fingerlings.
\end{abstract}

Keywords: Socio-environmental responsibility. Non-profit organization. Regional development. Sustainability.

\footnotetext{
1 Mestranda do Programa de Pós-Graduação em Ciências Contábeis e Administração da Unochapecó. evanilde@unochapeco.edu.br

2 Bacharel em Ciências Contábeis. edaiane@unochapeco.edu.br

${ }^{3}$ Doutor em Ciências Contábeis e Administração. Professor Titular do Programa de Pós-Graduação em Ciências Contábeis e Administração da Unochapecó. sady@unochapeco.edu.br

4 Doutora em Agronegócios. Professora Titular do Programa de Pós-Graduação em Ciências Contábeis e Administração da Unochapecó.gmores@unochapeco.edu.br
} 


\section{Introdução}

Os avanços tecnológicos que estimulam o aumento da produção, o incentivo ao consumo, a industrialização e as práticas de comercialização motivadas pela globalização, fazem emergir diferentes problemas sociais e ambientais. Esses problemas, por sua vez, criam demandas específicas às organizações do terceiro setor, como ações planejadas e organizadas, com foco em um objetivo comum: o desenvolvimento regional (FERNANDES; VASCONCELOS; VALADÃO JÚNIOR, 2014).

As Organizações do Terceiro Setor (OTSs) podem ser compreendidas como espaços institucionais que não se restringem a um setor, mas que materializam a realidade intersetorial e desenvolvem a cidadania (JUNQUEIRA, 2004). A promessa de renovação do espaço público, a busca pela solidariedade e cidadania e a superação da pobreza têm justificado a ascensão do terceiro setor no Brasil (FALCONER, 1999), dando espaço para as organizações com diferentes interesses e lógicas de atuação (ARAÚJO; MELO; SCHOMMER, 2005).

Outra forma de organização pode ser observada nas Organizações Não Governamentais (ONGs), que possuem variados objetivos, incluindo aquelas de caráter político e as com foco na implementação de projetos. Aquelas com foco em movimentos ambientalistas têm apresentado amadurecimento das práticas e atuação de instituições com ações proativas e propositivas, objetivando a sustentabilidade (JACOBI, 2003).

Os pontos que marcam a atuação de uma ONG consistem na credibilidade e no capital ético, na eficiência quando da intervenção na comunidade e na aplicação dos recursos. Por conhecerem a realidade social da região, conseguem propor estratégias e implementar projetos que atendam às necessidades da comunidade, promovendo a sustentabilidade e a equidade social (JACOBI, 2003).

Desta forma, o terceiro setor é uma denominação ampla, composto por organizações da sociedade civil, sem fins lucrativos, podendo ser classificado como entidades filantrópicas, igrejas, associações, entre outros. Essas organizações surgem em decorrência da ineficiência do Estado, com o objetivo de promover o desenvolvimento, propondo soluções para problemas sociais (MAÑAS; MEDEIROS, 2012). 
O terceiro setor emergiu na década de 1990, trazendo o compromisso de renovar o espaço público, resgatar a solidariedade e a cidadania, humanizar o capitalismo (ARAÚJO; MELO; SCHOMMER, 2005). Constituído no voluntariado e na filantropia, com um viés mais empresarial, é um setor que busca igualdade em relação ao Estado e ao mercado.

Apesar de se tratar de entidades sem finalidade econômica, as entidades com atuação no terceiro setor precisam desenvolver estratégias e práticas para suas atividades junto à comunidade, buscando harmonizar as ações sociais, econômicas e ambientais (SILVA; COSTA; GÓMEZ, 2011).

O Instituto Goio-En, com sede em Chapecó (SC), é uma entidade sem fins econômicos, com foco de atuação na área ambiental, sendo que os seus principais eixos de atuação se concentram no estudo dos peixes e na educação ambiental. Por meio de seus projetos e parcerias, promove junto à comunidade ações de estudo e educação ambiental, com o objetivo de promover o repovoamento e a preservação das espécies nativas que compõem a bacia hidrográfica do rio Uruguai. Promove também a conscientização e o manejo adequado das espécies, visando propiciar aos produtores, pescadores e ribeirinhos o melhoramento de técnicas de reprodução das espécies com maior potencial de comercialização.

Diante do exposto, este estudo busca responder à seguinte questão de pesquisa: Quais as principais práticas de responsabilidade socioambiental adotadas pelo Instituto Goio-En com vistas ao desenvolvimento regional? Para tanto, o objetivo do estudo é analisar as práticas de responsabilidade socioambiental adotadas pelo Instituto Goio-En para o desenvolvimento regional no seu âmbito de atuação.

O Instituto Goio-En assumiu, por meio de convênio junto à Usina Hidrelétrica Foz do Chapecó, localizada em Águas de Chapecó (SC), o compromisso de produzir alevinos nativos para o repovoamento do rio Uruguai. Com objetivo de reduzir o impacto ambiental causado pela instalação da usina, foi construída uma nova estação de piscicultura. A entidade vem atuando, desde a sua fundação, em ações e projetos, com princípios de responsabilidade social e ambiental, princípios de cooperação com entidades públicas e privadas, compromisso com o desenvolvimento regional, promoção da qualidade de vida e desenvolvimento sustentável, autonomia e sustentabilidade. 
O presente estudo visa contribuir de forma teórica e empírica com o tema abordado, investigando as práticas de uma entidade que tem como essência a prática de ações voltadas à responsabilidade socioambiental e o comprometimento com o desenvolvimento regional.

\section{Responsabilidade socioambiental das organizações}

O tema responsabilidade socioambiental tem apresentado avanços na literatura. Contudo, apresenta divergências no que diz respeito à aceitação por alguns segmentos de negócios (CALIXTO, 2008). Há evidências de que, nas décadas de 1960 e 1970, o tema responsabilidade social corporativa (RSC) começou a ser evidenciado na literatura, porém a adesão por parte das empresas e o apelo público tiveram ênfase a partir da década de 1990 (CALIXTO, 2008). Estudos como os de Van Aaken, Splitter e Seidl (2013), Fernández, JaraBertin e Pineaur (2015) e Tilt (2016) afirmam a crescente preocupação em relação à RSC.

As pressões sociais motivam as organizações a justificarem a sua atuação social em uma perspectiva de continuidade, pois a sua sobrevivência depende da relação estabelecida com os stakeholders (GEORGETA, 2008). Com isso, é crescente o número de organizações em todo mundo que estão incorporando atividades de responsabilidade social e evidenciando as informações sociais e ambientais aos seus usuários (GEORGETA, 2008; TILT, 2016).

A RSC pode ser definida como um conjunto de atividades desenvolvidas por empresas que promovem o bem-estar social, que estão além dos interesses primordiais da empresa e da exigência legal (MCWILLIANS; SIEGEL, 2001). Contudo, esta é apenas uma das compreensões sobre a RSC, existindo outros entendimentos que, por vezes, não estão claros, o que dificulta o desenvolvimento teórico (MCWILLIANS; SIEGEL; WRIGTH, 2006).

Na concepção de Zhao e Du (2017), a RSC significa integrar voluntariamente questões sociais e ambientais nas atividades das empresas e nas relações com as partes interessadas, sacrificando lucros em benefício de interesses sociais. A RSC foi proposta com a finalidade de incorporar características sociais nos produtos e seus processos de fabricação, utilizando técnicas de preservação do meio ambiente (MCWILLIANS; SIEGEL; WRIGTH, 2006). 
Ao adotarem um comportamento socialmente responsável, as empresas tornam-se importantes agentes de mudanças, assumindo parcerias com o Estado e a sociedade civil, visando a uma sociedade econômica e socialmente mais justa (RICO, 2004; BIER; BASSAN, 2015). Esta é uma postura desejada, pois a sociedade está mais exigente no que se refere às expectativas e aos interesses em relação àquilo que as empresas devem fornecer para atender ao estilo de vida das pessoas (GEORGETA, 2008).

É importante para as organizações conhecerem as expectativas e necessidades das partes interessadas; desse modo, poderão adotar práticas que ofereçam benefícios aos interessados, visando manter o equilíbrio econômico, social e ambiental (FERNÁNDEZ; JARABERTIN; PINEAUR, 2015). Adicionalmente, a relevância é manifestada em razão de que as empresas empregam esforços para que suas ações atendam aos interesses do seu público interno e externo (CALIXTO, 2008).

Alguns fatores externos, a exemplo das exigências legais, das pressões da sociedade, ou acionistas, motivam as companhias a adicionarem à sua cultura organizacional os princípios e valores socioambientais, incorporando ações que visem mitigar e prevenir os impactos ocasionados pela execução de suas atividades (OLIVEIRA et al., 2016).

No entanto, essa crescente preocupação com o bem-estar social também pode ser atribuída às organizações sociais. Conforme argumentam Muraro e Lima (2003), as pessoas estão buscando participar mais ativamente das decisões que se referem ao seu modo de viver. Nesse sentido, o terceiro setor amplia suas dimensões, motivando a sociedade a envolver-se em ações que não visem somente ao lucro, mas também melhorar os aspectos sociais dos envolvidos.

Os problemas sociais vivenciados no país têm sido uma das principais razões para o surgimento e a expansão do terceiro setor no Brasil (MURARO; LIMA, 2003). Uma das principais ações do terceiro setor é o contraponto às ações do mercado, cuja presença indica que o mercado gerou uma demanda que é incapaz de satisfazer, servindo-se de recursos (humanos e ambientais, por exemplo) que não é capaz de repor. Nesse sentido, fazem-se necessários investimentos sem fins lucrativos para suprir tais demandas (FERNANDES, 1997).

Ashley $(2003$, p. 6) conceitua a responsabilidade social como o "[...] compromisso que uma organização deve ter com a sociedade, expresso por meio de atos e atitudes que a 
afetem positivamente, $[. .$.$] , agindo pro ativamente e coerentemente no que tange a seu$ papel específico na sociedade e a sua prestação de contas para com ela". Assim, pela concepção institucional, as entidades do terceiro setor são motivadas pelo compromisso com a responsabilidade social.

As OTSs estão ocupando lugares estratégicos no sistema de governança global, conquistando posições capazes de interferir nas práticas socioambientais das empresas. Sua atuação consiste, principalmente, na exigência de que as empresas atuem dentro do modelo de sustentabilidade, incorporando seus princípios nas operações, relação com a sociedade e preservação dos recursos naturais (COSTA; RAMOS; PORTELA, 2014).

Para desenvolver suas ações socioambientais, as OTSs buscam parcerias com as demais organizações do primeiro e segundo setores. As colaborações intersetoriais têm se apresentado como estratégia entre as organizações para viabilizar projetos nesse âmbito (FISCHER, 2005). Ao mesmo tempo em que as colaborações entre os setores são benéficas para as empresas, uma vez que conseguem desenvolver projetos de cunho social e ambiental, também beneficiam as OTSs. Por meio dos recursos financeiros, materiais e das ações voluntárias oriundas dessas parcerias, as OTSs têm a possibilidade de concretizar seus projetos. A inexistência desse apoio, muitas vezes, inviabiliza a obtenção de seus objetivos em razão de suas dificuldades, especialmente financeiras (VEIGA-NETO; PANHOSSI; GODOY, 2004).

\section{Sustentabilidade}

Na concepção de Ruscheinsky (2003, p. 43), “[...] o termo sustentabilidade refere-se à capacidade de um modelo ou sistema sustentar-se na dinâmica evolutiva, sem permitir que algum setor se aprofunde em crises, de tal forma que venha a atingir a totalidade".

Uma definição de sustentabilidade amplamente utilizada é o conceito dado pela World Commissionon Environmentand Development (WCED, 1987), a qual concebe a sustentabilidade como o desenvolvimento de ações que atendam às atuais necessidades sem comprometer a capacidade das gerações futuras de atender às suas necessidades. A partir deste entendimento, muitas organizações implementaram programas ambientais e práticas 
sociais em suas atividades, por compreenderem que a definição dada pela WCED agrega questões econômicas, sociais e ambientais (GIMENEZ; SIERRA; RODON, 2012).

No entendimento de Elkington (2012, p. 52), a sustentabilidade "[...] é o princípio que assegura que nossas ações de hoje não limitarão a gama de opções econômicas, sociais e ambientais disponíveis para as futuras gerações", apresentando-a fundamentada em três pilares: o econômico, o social e o ambiental. A forma de operacionalização e avaliação da sustentabilidade ocorre frequentemente com a utilização de três pilares (Triple Bottom Line TBL), um conceito proposto por John Elkington, em 1994, em sua obra Cannibals with Forks: The Triple Bottom Line of 21st Century Business. A apresentação dos três pilares, ou do conceito TBL, engloba a consideração dos 3Ps: profit (lucro), planet (planeta) e people (pessoas).

O desafio da sustentabilidade torna-se complexo ao considerar que os três pilares não são estáveis e sofrem pressões sociais, políticas, econômicas e ambientais, que provocam fluxos constantes e, à medida que as pressões ocorrem, movem-se, podendo causar impactos nos demais (ELKINGTON, 2012).

A sustentabilidade econômica normalmente é a mais compreendida, pois pode ser mensurada facilmente, a exemplo do custo de produção, que é um fator impactante na situação econômica da organização (GIMENEZ; SIERRA; RODON, 2012). A sustentabilidade ambiental está associada à redução de resíduos, redução de poluição, uso adequado dos materiais e insumos (PULLMAN; MALONI; CARTER, 2009). A sustentabilidade social está relacionada às oportunidades e incentivos, à diversidade que as organizações promovem dentro e fora da comunidade e visa assegurar qualidade de vida, processos democráticos e estruturas responsáveis de governança (ELKINGTON, 1994).

Como decorrência, organizações começaram a divulgar o seu desempenho econômico, ambiental e social pelo conceito TBL, por se tratar de um modelo atrativo para as organizações (OLIVEIRA et al., 2012). Uma justificativa plausível é a de que o modelo TBL acrescenta medidas de desempenhos sociais e ambientais às medidas econômicas, atendendo às responsabilidades das empresas, que são mais amplas que simplesmente gerar lucro (HUBBARD, 2009). 
Além das empresas, as organizações sem fins lucrativos também estão adotando o conceito TBL. Diversas organizações sem fins lucrativos juntam-se às empresas privadas para abordar questões de sustentabilidade que afetam mutuamente as partes interessadas. As empresas compreendem que o envolvimento com organizações dessa natureza fortalece os vínculos comerciais. O conceito TBL pode ser aplicado também às comunidades, com o objetivo de estimular o desenvolvimento sustentável. Para isso, é importante haver cooperação entre empresas, organizações sem fins lucrativos, governo e população envolvida (SLAPER; HALL, 2011).

No contexto das organizações do terceiro setor, a sustentabilidade representa a garantia da viabilidade econômica da organização, assegurando o eficaz atendimento das demandas dos grupos beneficiados. Nesse sentido, a ideia de sustentabilidade no terceiro setor requer mudanças, passando por um processo de transição de um modelo assistencialista para um modelo de autossustentação. Para isso, são necessárias mudanças de postura institucional em relação aos processos gerenciais e novas perspectivas de relacionamentos e articulações (VALADÃO JÚNIOR; MALAQUIAS; SOUSA, 2008).

A falta de recursos financeiros tem sido um dos principais desafios enfrentados pelas organizações do terceiro setor; com isso, surgem as dificuldades de continuidade. Visando superar essas dificuldades, as organizações buscam formas variadas de atuação e fomento. Uma das formas que vêm se destacando são as parcerias intersetoriais (PARENTE et al., 2012). As parcerias intersetoriais, firmadas entre organizações do terceiro setor com os demais setores, têm por objetivo implementar projetos que visem beneficiar uma comunidade, desenvolvendo ações de interesse público (FISCHER, 2005).

As organizações buscam evidenciar as suas informações socioambientais, no intuito de avaliar o seu desempenho. Podem ser citados os indicadores Ethos para negócios sustentáveis e responsáveis, utilizados por empresas para avaliar o seu desempenho socioambiental, e considerados neste estudo para compreender o Instituto Goio-En e as suas dimensões.

As quatro dimensões que compõem os indicadores Ethos seguem o conceito ESG (Environmental, Social and Governance - Ambiental, Social e Governança), complementado pela dimensão visão e estratégia, que busca conhecer a forma como as organizações 
implementam em suas estratégias a temática responsabilidade social e sustentabilidade. A dimensão governança e gestão trata de temas que orientam as organizações a alinharem a sua gestão aos conceitos de responsabilidade social e sustentabilidade, compreendendo a proposição e a implementação de políticas, bem como a sua integração nos processos de gestão. No que se refere à dimensão social, busca identificar políticas e mecanismos adotados pelas organizações, a fim de garantir a preservação dos direitos humanos, quer em seu quadro (funcionários e clientes) quer na comunidade em que está inserida. A dimensão ambiental visa conhecer as ações das organizações relacionadas à preservação e conservação do meio ambiente e dos recursos naturais (INSTITUTO ETHOS, 2017).

\section{Procedimentos metodológicos}

A pesquisa empreendida analisou as práticas socioambientais do Instituto Goio-En, à luz de suas contribuições para o desenvolvimento regional no seu âmbito de atuação. Em relação ao objetivo, o estudo caracterizou-se como descritivo, uma vez que buscou analisar os fatos relacionados àquela realidade específica (TRIVIÑOS, 2006). Quanto à abordagem do problema, utilizou-se a forma qualitativa, ao considerar um caso concreto e as suas particularidades (FLICK, 2009). Em relação aos procedimentos, trata-se de um estudo de caso, ao investigar "[...] um fenômeno contemporâneo dentro de seu contexto da vida real" (YIN, 2015, p. 17).

O ambiente de estudo selecionado foi o Instituto Goio-En, em decorrência de sua atuação com o tema pesquisado. Instituído em 2003, na forma de organização de estudo, pesquisa, desenvolvimento e serviços, o Instituto tem um compromisso com a responsabilidade ambiental e o desenvolvimento regional. Atua em três eixos principais: estudo dos peixes, educação ambiental e planejamento urbano.

A Fundação de Desenvolvimento do Oeste (Fundeste) é a entidade mantenedora do Instituto Goio-En, respondendo também pela manutenção da Universidade Comunitária da Região de Chapecó (Unochapecó), que mantém atividades em parceria.

No estudo dos peixes, o Instituto Goio-En desenvolve pesquisas relacionadas aos peixes da bacia hidrográfica do rio Uruguai e realiza ações de incentivo à piscicultura regional. Com relação à educação ambiental, o Instituto promove um conjunto de atividades 
que buscam sensibilizar diferentes públicos, resgatando a importância em preservar relações e atitudes socioambientais responsáveis, estimulando os indivíduos a serem multiplicadores ambientais. No planejamento urbano, atua em parceria com prefeituras, no desenvolvimento de planos diretores, planos municipais de saneamento básico, planos locais de habitação de interesse social e boletins cadastrais imobiliários. Neste campo, são sugeridas estratégias, medidas e ações, a fim de ordenar e estruturar o meio urbano e rural (INSTITUTO GOIO-EN, 2017c).

Como técnica de coleta de dados, utilizou-se a entrevista estruturada. As questões foram elaboradas com base nas quatro dimensões propostas pelo Instituto Ethos, no documento Indicadores Ethos para negócios sustentáveis e responsáveis, ciclo 2016/2017, conforme o Quadro 1, inserido na próxima página.

As entrevistas foram guiadas por um roteiro de questões, as quais nortearam o diálogo com os entrevistados. Foram entrevistados três gestores com implicação direta na gestão do Instituto. Após a análise dos dados, tendo em vista a profundidade e o grau de concordância observados nas respostas, considerou-se suficiente o número de entrevistados. As entrevistas foram gravadas e transcritas, com a autorização dos entrevistados, para posterior análise de conteúdo.

As entrevistas ocorreram entre 7 e 10 de agosto de 2017, com duração total de 4 horas e 39 segundos, gerando um total de 38 páginas transcritas. Todas as entrevistas foram realizadas nos locais de trabalho dos entrevistados, cujos nomes foram preservados nesta pesquisa. A arguição com o Entrevistado 1 durou 1:46:39h e gerou dezessete páginas de transcrição. O Entrevistado 2 foi ouvido durante $00: 38: 18 \mathrm{~h}$, e foram produzidas oito páginas de transcrição. Com o Entrevistado 3, o tempo da entrevista foi de 1:35:42h, e foram produzidas treze páginas de transcrição. 


\section{Quadro 1: Instrumento de coleta de dados}

\begin{tabular}{|c|c|c|}
\hline Dimensão & Temas abordados & Questões \\
\hline \multirow{3}{*}{$\begin{array}{l}\text { Visão e } \\
\text { estratégia }\end{array}$} & \multirow{3}{*}{$\begin{array}{l}\text { Estratégias para a } \\
\text { sustentabilidade; } \\
\text { Proposta de valor; } \\
\text { Modelo de negócios. }\end{array}$} & $\begin{array}{l}\text { De que forma os aspectos de sustentabilidade estão incorporados nas } \\
\text { estratégias e nos planos de atuação do Instituto Goio-En? }\end{array}$ \\
\hline & & $\begin{array}{l}\text { Em quais aspectos principais a incorporação dos princípios de } \\
\text { sustentabilidade torna-se um diferencial na atuação do Instituto Goio- } \\
\text { En na promoção do desenvolvimento regional? }\end{array}$ \\
\hline & & $\begin{array}{l}\text { Quais os tipos de investimentos realizados em pesquisa e } \\
\text { desenvolvimento voltados para a inovação em sustentabilidade? }\end{array}$ \\
\hline \multirow{3}{*}{$\begin{array}{l}\text { Governança } \\
\text { e gestão }\end{array}$} & \multirow{3}{*}{$\begin{array}{l}\text { Governança } \\
\text { organizacional; } \\
\text { Práticas de operação } \\
\text { e gestão. }\end{array}$} & $\begin{array}{l}\text { Quais as medidas adotadas pela gestão do Instituto Goio-En para } \\
\text { garantir o desempenho de suas atividades de forma ética e com } \\
\text { envolvimento político responsável? }\end{array}$ \\
\hline & & $\begin{array}{l}\text { De que forma os aspectos sociais e ambientais impactam a gestão } \\
\text { econômica do Instituto Goio-En? }\end{array}$ \\
\hline & & $\begin{array}{l}\text { Quais as iniciativas adotadas pelo Instituto Goio-En que visam ao } \\
\text { diálogo e à participação das partes interessadas em seu processo de } \\
\text { gestão e tomada de decisão? }\end{array}$ \\
\hline \multirow{3}{*}{ Social } & \multirow{3}{*}{$\begin{array}{l}\text { Direitos humanos; } \\
\text { Práticas de trabalho; } \\
\text { Envolvimento com a } \\
\text { comunidade e seu } \\
\text { desenvolvimento. }\end{array}$} & $\begin{array}{l}\text { Quais as ações desenvolvidas pelo Instituto Goio-En com o objetivo de } \\
\text { acompanhar e evitar que suas atividades não infrinjam os princípios } \\
\text { dos direitos humanos (não comprar insumos de fornecedores que } \\
\text { tenham envolvimento com trabalho infantil/escravo, promover a } \\
\text { diversidade e equidade)? }\end{array}$ \\
\hline & & $\begin{array}{l}\text { Em relação ao quadro de funcionários, quais ações o Instituto Goio-En } \\
\text { desenvolve com vistas a garantir seus direitos, o desenvolvimento } \\
\text { pessoal e profissional? }\end{array}$ \\
\hline & & $\begin{array}{l}\text { Quais os principais objetivos e perspectivas do Instituto Goio-En em } \\
\text { relação ao desenvolvimento da comunidade regional? }\end{array}$ \\
\hline \multirow{3}{*}{ Ambiental } & \multirow{3}{*}{ Meio ambiente } & $\begin{array}{l}\text { Quais ações, atividades e projetos são desenvolvidos pelo Instituto } \\
\text { Goio, no seu âmbito de atuação, com o objetivo de recuperar e } \\
\text { preservar o ecossistema? }\end{array}$ \\
\hline & & $\begin{array}{l}\text { De que forma o Instituto Goio-En avalia a implementação de ações e } \\
\text { políticas para o uso sustentável dos recursos naturais? }\end{array}$ \\
\hline & & $\begin{array}{l}\text { Considerando que o Instituto Goio-En é uma organização de estudos, } \\
\text { pesquisas e educação ambiental, quais as ações desenvolvidas para } \\
\text { disseminar a importância do abrandamento do impacto ambiental na } \\
\text { exploração das atividades econômicas, na sua região de abrangência? }\end{array}$ \\
\hline
\end{tabular}

Fonte: Elaborado pelos autores com base em Instituto Ethos (2017).

Para a análise dos dados, foi utilizada a análise de conteúdo, que, de acordo com Bardin (2011), é uma técnica de investigação que tem por objetivo a análise de comunicações, por meio de procedimentos sistemáticos e descrição objetiva, visando à interpretação dessas comunicações. A análise documental foi efetuada posteriormente. Foram realizados exames nos documentos fornecidos pela mantenedora, especialmente os balanços sociais de 2010 a 2016. Informações adicionais foram pesquisadas no site do instituto e de sua mantenedora. 


\section{Resultados e discussão}

Nesta seção, são sumarizadas as arguições obtidas, no sentido de analisar as práticas desenvolvidas pela entidade investigada e as suas contribuições em prol do desenvolvimento regional. A partir das questões elaboradas, foi possível compilar as principais percepções dos gestores em relação à atuação da entidade investigada e de sua contribuição com a comunidade regional.

\subsection{Visão e estratégia}

Os entrevistados ressaltam que, atualmente, a sustentabilidade econômicofinanceira do Instituto é deficitária, em razão do custo de manutenção da estação de piscicultura, localizada em Águas de Chapecó/SC, construída em parceria com a Usina Hidrelétrica Foz do Chapecó (UHFC) e o Ministério da Pesca e Aquicultura (atual Secretaria de Aquicultura e Pesca).

A partir da construção da usina hidrelétrica no rio Uruguai, em 2010, a Foz do Chapecó assumiu a obrigatoriedade de compensações ambientais. A estação de piscicultura integra uma das ações, no intuito de produzir alevinos nativos para repovoamento do rio e lagos ao longo da barragem. A UHFC investiu recursos na estação, e o Instituto assumiu o compromisso da reprodução das espécies (Entrevistado 3).

A UHFC, com o objetivo de aumentar a população de peixes na bacia do rio Uruguai e atender às responsabilidades decorrentes do licenciamento ambiental da Usina, firmou convênio com a Fundeste e o Instituto Goio-En, para a construção da estação de piscicultura (FOZ DO CHAPECÓ..., 2017), conforme o termo de Convênio FCE-088/2009, ora administrada pelo Instituto.

Embora a atuação do Instituto não esteja restrita a este compromisso, ele resulta em uma efetiva ação ambiental, já que o repovoamento do rio e dos lagos concede ao Instituto, à Fundeste e à Unochapecó o cumprimento de uma função social importante (Entrevistado 2). Esse entendimento é destacado pelo Entrevistado 1, ao argumentar que "O nosso 
principal objetivo não é manter as espécies no rio, mas manter o estoque pesqueiro para aquele ribeirinho que sobrevive disso, esse é o nosso maior papel social".

Outra preocupação do Instituto consiste no desenvolvimento regional, uma vez que a estação de piscicultura se revela um projeto inovador, com investimentos no aprimoramento genético, efetuando-se diversos controles, com foco na produção de alevinos de qualidade. Para isso, o Instituto tem trabalhado no aprimoramento da produção de peixes nativos, buscando alto padrão genético, por meio de rigoroso controle do processo (Entrevistado 1).

O Instituto mantém em seus arquivos planilhas eletrônicas dos controles e acompanhamentos realizados durante o processo, incluindo controles diários (a exemplo da qualidade da água, alimentação) e controles permanentes (a exemplo da biometria das matrizes, dados de desova e controle de manejo).

Os entrevistados ressaltam que, historicamente, o Instituto tem atuado junto à comunidade, com foco na sustentabilidade e desenvolvimento da população envolvida. Dentre as atividades realizadas com esse foco, estão a elaboração de planos diretores e a educação ambiental, com maior ênfase na última, devido à sua abrangência e envolvimento, especialmente com a população ribeirinha, colônias de pescadores, crianças e educadores.

A Fundeste, por meio de suas mantidas (Instituto Goio-En e Unochapecó), tem responsabilidade significativa na promoção do desenvolvimento regional, tendo o Instituto se destacado na realização de atividades relacionadas à educação ambiental. O Instituto também atua na educação ambiental por meio de parcerias, ou ações próprias, pois compreende que, além da criação dos alevinos, transmitir conhecimentos faz parte da sustentabilidade (Entrevistado 3).

Observou-se que o Instituto consiste em um vasto campo de pesquisa, aplicada a diversas áreas do conhecimento. No âmbito de projetos de pesquisa vinculados aos cursos de pós-graduação da Unochapecó, a maior ênfase ocorreu no estudo dos peixes, porém, nos últimos anos, devido à migração de professores pesquisadores para outras instituições e à redução de editais públicos de fomento à pesquisa, o número de pesquisas reduziu. Conforme ressalta o Entrevistado 2, o Instituto é um amplo espaço de desenvolvimento e produção do conhecimento, que poderia estar associado aos programas de pós-graduação 
da instituição. No entanto, devido ao seu caráter comunitário, a universidade tem encontrado dificuldades em fomentar esses projetos, uma vez que editais específicos para este tipo de entidade são raros.

Por outro lado, houve um avanço significativo em projetos que visam à melhoria na produção dos alevinos. De acordo com os entrevistados, por se tratar de produção de peixes nativos, o processo produtivo é mais delicado. Nesse sentido, diversas etapas do processo precisaram ser melhoradas. Para tanto, os professores e a equipe técnica do Instituto vêm desenvolvendo diversas pesquisas.

Os resultados das melhorias efetuadas no processo produtivo foram observados nos relatórios do Instituto. Em 2012, no primeiro ano de soltura, cinco mil alevinos foram devolvidos ao rio. O número cresceu gradativamente, sendo que, na safra 2015/2016, o Instituto atingiu a maior produção, com mais de quinhentos mil alevinos devolvidos ao rio Uruguai (FUNDESTE, 2012; 2016).

Nesse sentido, visando à sustentabilidade do Instituto e da estação de piscicultura, busca-se permanentemente a inovação dos processos, o uso de novas tecnologias e de conhecimento das atividades produtivas, para gerar resultado econômico. Um dos exemplos citados refere-se à troca do chip utilizado para a marcação dos peixes, que resultou em uma economia anual de cerca de $80 \%$ do valor anteriormente gasto, sem comprometer o monitoramento (Entrevistado 1).

\subsection{Governança e Gestão}

As atividades do Instituto são norteadas por princípios éticos de governança, os quais incluem observância à legislação vigente, uso de tecnologias limpas, especialmente no processo de limpeza e na conservação da estação de piscicultura. No processo produtivo, são atendidos os princípios de sanidade e bem-estar animal, além da preocupação com a comunidade na qual o Instituto está inserido, como, por exemplo, o compromisso com os pescadores que fornecem os peixes (matrizes) (Entrevistado 1).

Tanto na recepção das matrizes quanto na soltura dos alevinos, são realizados procedimentos de vistoria de defeitos, em atendimento à ABNT NBR 5426. Também os 
alevinos são submetidos a testes de sanidade animal por um funcionário responsável. Os procedimentos e laudos são realizados de acordo com a legislação ambiental.

Outro aspecto destacado pelos entrevistados refere-se ao escopo de atuação do Instituto e à atual forma de governança. Quanto ao escopo de atuação, observa-se que o Instituto precisa rever esse seu espaço e buscar ampliá-lo, visando à própria sustentabilidade, uma vez que conta apenas com recursos subsidiados pela Fundeste (mantenedora) e pela sua coirmã institucional (Unochapecó). Com vistas à sustentabilidade, o Instituto encontra-se em um momento de discussão acerca do modelo de gestão, podendo ser instituído um novo modelo de desenvolvimento. Conforme destaca o Entrevistado 2, essa discussão pode levar a gestão a pensar um novo modelo de governança. Atualmente, o Instituto, na condição de instituição mantida, tem gestão própria, o que pode gerar distanciamentos, especialmente dos programas de pós-graduação stricto sensu da Unochapecó.

O Instituto, juntamente com a Fundeste, está reavaliando as suas estratégias de atuação. São vistas como boas estratégias a comercialização de alevinos e a captação de recursos por meio de parcerias e convênios, cursos da Unochapecó e instituições públicas ou privadas. Para efetivar esse processo, o Entrevistado 3 destaca que o Instituto tem buscado o auxílio da Universidade, uma vez que o mesmo detém um amplo conhecimento técnico, mas reduzido em termos administrativos.

A produção de alevinos para a comercialização vem sendo estudada, conforme o que foi destacado pelos entrevistados e apresentado em relatórios internos. O crescimento da produção, na safra 2015/2016, possibilitou cumprir com o convênio estabelecido com a UHFC e disponibilizar alevinos para a venda. Nesse sentido, pesquisas estão sendo desenvolvidas com vistas ao cultivo comercial (FUNDESTE, 2016).

Mesmo que as organizações que compõem o terceiro setor não visem ao lucro, dependem do resultado econômico para garantir a sua sustentabilidade financeira. Foster e Bradach (2005) destacam que as OTSs precisam incorporar em suas estratégias iniciativas de renda e ganho, reduzindo a dependência de angariar fundos com outras organizações. Nesse contexto, as OTSs estão buscando alternativas que garantam a sua sustentabilidade financeira, gerando fontes próprias de renda por meio da produção ou comercialização de 
produtos ou serviços (SILVA, 2010). As ações do Instituto pesquisado estão alinhadas com esta preocupação.

As ações sociais e ambientais impactam de forma direta na gestão econômica do Instituto, especialmente por conta das mudanças legais e econômicas. Como não há obrigatoriedade legal de manter a educação ambiental nas escolas, por exemplo, torna-se difícil a captação de recursos para essa atividade (Entrevistado 3).

Também pode ser observado que o fator econômico produz impactos nas ações ambientais, pois, quando há mudanças negativas no cenário econômico, há uma redução dos investimentos em relação às questões socioambientais. Diante disso, a gestão tem buscado soluções alternativas para gerar economia e não prejudicar o processo produtivo ou comprometer a qualidade dos alevinos (Entrevistado 1).

Em relação às restrições causadas pelo fator econômico, Jentz et al. (2015) apresentam uma situação semelhante, ao analisarem como as dimensões social, ambiental e econômica interferem na condução das atividades de uma ONG. Os achados da pesquisa revelam que as restrições econômicas limitam a abrangência do projeto, podendo comprometer a qualidade e a continuidade de suas ações.

Apesar do Instituto não apresentar resultado econômico suficiente para a sua manutenção, a sua mantenedora não demonstra intenção de reduzir as suas ações, conforme foi mencionado pelo Entrevistado 2:

O Instituto não apresenta sustentabilidade econômica, quem sabe a gente poderia
reduzir alguns esforços na área ambiental para que ele pudesse ter um resultado
mais efetivo. Mas não há essa preocupação, a instituição tem um olhar muito
amplo nesse sentido e acredita muito na necessidade, por exemplo, da
preocupação com área ambiental.

Observa-se a compreensão dos gestores sobre a importância das ações do Instituto, especialmente na área ambiental, empenhando esforços para produzir em condições de excelência. Nesse contexto, o impacto socioambiental das ações do Instituto é considerado efetivo.

As decisões e encaminhamentos do Instituto ocorrem nos conselhos, instituídos e formalizados conforme princípios da Fundeste (mantenedora), formados por representantes de entidades da sociedade civil e do poder público, a exemplo da Empresa de Pesquisa Agropecuária e Extensão Rural de Santa Catarina (EPAGRI), da Associação dos Municípios do 
Oeste de Santa Catarina (AMOSC), de prefeituras da região e da Unochapecó. A atuação dos conselhos é efetiva, com aprovação, por exemplo, do orçamento e da prestação de contas do Instituto. A composição e competências do Conselho Consultivo e da Direção estão regulamentadas no Regimento Interno do Instituto, e os demais conselhos são regidos pelas normativas da Fundeste (mantenedora).

Todas as decisões relacionadas às mantidas são levadas aos Conselhos da Fundeste, o que não implica, necessariamente, na participação das outras mantidas. Entretanto, a Unochapecó participa ativamente nas principais decisões relacionadas ao Instituto, com cuja atuação a Universidade tem relação direta.

\subsection{Social}

Destaca-se a preocupação da Fundeste e de suas mantidas em relação aos aspectos sociais, especialmente, os que envolvem os funcionários e a comunidade local. As ações da Fundação são norteadas por princípios e diretrizes estabelecidos, formalizados e amparados na legislação. As ações desenvolvidas pelo Instituto atendem a normas e diretrizes de sua mantenedora, que tem como premissa a transparência e a clareza dos processos, por meio do uso compartilhado dos sistemas, tais como sistema de compras, de contratação de pessoal, jurídico e contábil (Entrevistado 3).

Além das exigências legais, a Fundeste preocupa-se com outras necessidades básicas de seus funcionários, como, por exemplo, saúde, segurança e condições de trabalho. Para que isso ocorra, há uma parceria com a Universidade, visto que todos os processos de contratação e relacionamento com os funcionários ocorrem via Diretoria de Desenvolvimento Humano (DDH) da Unochapecó, conforme constatado na fala do Entrevistado 3: "As normas estabelecidas pela Fundeste foram criadas dentro da Unochapecó, elas valem para todas as instituições que integram a Fundeste, os mesmos direitos".

Pelo caráter comunitário da Universidade e por se tratar de uma instituição de ensino superior, há um controle social efetivo, especialmente no que se refere às condições de trabalho. A instituição oferece plano de cargos, salários e carreira; bolsas de estudo; plano de saúde; plano de previdência; além de disponibilizar outros benefícios por meio de 
parcerias e convênios com entidades e empresas. Além disso, os funcionários participam ativamente das discussões e decisões da instituição (Entrevistado 2).

O funcionário tem a oportunidade de aperfeiçoamento profissional e pessoal, por meio de incentivos para estudar. Para isso, além das bolsas ofertadas, os horários de trabalho são flexibilizados, possibilitando ao funcionário ajustar o seu horário de trabalho. Observa-se, portanto, a valorização dada aos funcionários, conforme destacado pelo Entrevistado 1: "Se eu não cuido da equipe, eu não tenho resultado, eu não gerencio pessoas, eu me relaciono com elas".

Em relação ao desenvolvimento da comunidade regional, ficou evidenciado que a atuação do Instituto junto à comunidade já foi mais abrangente, com atuação em vários municípios dos estados de Santa Catarina e do Rio Grande do Sul, especialmente com o projeto de educação ambiental.

Devido à situação econômica do país, as atividades do Instituto estão mais restritas aos municípios de Águas de Chapecó e São Carlos (SC), considerando as instalações do Instituto e da usina hidrelétrica. Historicamente, o Instituto tem realizado ações no que se refere ao desenvolvimento de pescadores, inclusive com ações de organização das pessoas diretamente atingidas (Entrevistado 1).

A educação ambiental e o repovoamento do rio são considerados, atualmente, ações diretas de desenvolvimento das comunidades, especialmente as ribeirinhas. Com essas ações, o Instituto busca ser reconhecido como uma instituição comprometida com os aspectos socioambientais, cujo objetivo é amenizar os impactos negativos causados aos ribeirinhos pelos empreendimentos hidrelétricos (Entrevistado 3).

Além das ações de soltura previstas pelo convênio, o Instituto realiza ações de soltura por meio de parcerias e de doações a cursos e entidades, a exemplo da ação realizada em 2017, em conjunto com acadêmicos do curso de Administração da Unochapecó, ocasião em que foram soltos 3.200 alevinos no rio Uruguai, e da ação de apoio ao Projeto "Repovoamento da Bacia Hidrográfica de Nova Erechim", pela Polícia Militar do referido município, com a soltura de 3.300 alevinos no rio Burro Branco (INSTITUTO GOIO-EN, 2017a). Com o objetivo de retomar atividades, o Instituto busca parcerias e convênios com 
instituições públicas e privadas, instituições de ensino superior e empresas em geral, o que possibilitará expandir sua atuação e área de abrangência.

\subsection{Ambiental}

Na esfera ambiental, a ação de maior importância do Instituto refere-se à execução do Projeto Piraqué. A criação dos peixes para o repovoamento do rio Uruguai é tida como a principal ação do Instituto em contribuição ao ecossistema. O objetivo de produzir alevinos não se resume a uma ação contratual, mas povoar o rio, contribuindo com a recuperação das espécies nativas (Entrevistado 3).

Outro aspecto refere-se ao uso adequado dos recursos naturais. Princípios de preservação desses recursos foram incorporados ao Instituto, havendo um compromisso institucionalizado nesta perspectiva. O Instituto tem o cuidado de não utilizar em seus processos produtivos produtos químicos que agridam o meio ambiente. Mesmo que o montante de água utilizado pela estação seja irrisório em relação ao montante de água do rio, há um cuidado no tratamento da água. Assim, as atividades desenvolvidas atendem às normas técnicas e ambientais de qualidade.

Constataram-se, nos registros do Instituto, relatórios de análises periódicas de controle de qualidade, entre eles, relatórios de qualidade da água captada do rio e da água devolvida ao rio. Os resultados analíticos fazem parte do escopo de controle de processos realizados pela estação.

O Instituto apresenta algumas limitações de atuação junto à comunidade devido à condição econômica. Uma atuação relevante do Instituto trata-se do projeto de educação ambiental, desenvolvido entre 2007 e 2016, em parceria com a UHFC. O projeto visava identificar o perfil e a realidade das comunidades, a fim de sensibilizar sobre a importância de resgatar, construir e preservar relações e atitudes socioambientais responsáveis, estimulando nos participantes a ideia de se tornarem multiplicadores da educação ambiental (Entrevistado 1).

A partir de 2013, o projeto voltou-se para o desenvolvimento de ações com o objetivo de instigar o desenvolvimento de ocupações e fonte de renda provenientes dos 
resíduos ou materiais encontrados nas propriedades. 0 projeto atendeu quatorze municípios, em parceria com as Secretarias Municipais de Agricultura e Educação (Entrevistado 1). De acordo com dados coletados nos relatórios do Instituto, em 2014 e 2015, foram atendidas cerca de 1.400 e 1.800 pessoas, respectivamente. Em 2016, os atendimentos foram próximos a 1.000, com cerca de noventa atividades realizadas (FUNDESTE, 2014; 2015; 2016). Todas as atividades contêm registro de presença, e as oficinas realizadas com agentes de saúde, agentes comunitários e professores foram certificadas como cursos de extensão pela Diretoria de Extensão da Unochapecó.

Atualmente, a execução desse projeto ocorre com a participação em feiras, exposições e atividades de conscientização. Para retomar o projeto em sua essência, o Instituto precisa melhorar a sua condição econômica, e, para isso, estão em fase de elaboração projetos que visam à captação de recursos, a exemplo da comercialização de alevinos, e formalização de convênios com entidades parceiras. Com isso, seria possível retomar e expandir a área de atuação do Instituto e da própria estação de piscicultura, abrangendo as colônias de pescadores estabelecidas na região (Entrevistado 3).

Falconer (1999) enfatiza que a sustentabilidade da OTS, no longo prazo, depende de sua capacidade de captar e gerir recursos (financeiros, materiais ou humanos) de forma suficiente e continuada, permitindo perpetuar a organização e alcançar os seus objetivos. Contudo, o autor destaca a dificuldade dessas organizações angariarem recursos.

Para a captura de matrizes adquiridas pelo Instituto, este mantém parcerias com os pescadores da região, os quais foram capacitados para tal finalidade. Por meio da soltura dos alevinos, o Instituto contribui diretamente com o repovoamento do rio Uruguai e seus afluentes, mantendo a biodiversidade dos rios e contribuindo indiretamente para a economia da população ribeirinha, visto melhorar as condições de pesca àquela população (Entrevistado 1).

De acordo com a Foz do Chapecó... (2017), o projeto desenvolvido em parceria já promoveu a soltura de aproximadamente 1.500 .000 alevinos. A soltura constante de alevinos visa contribuir com a manutenção dos estoques pesqueiros na bacia hidrográfica do rio Uruguai. Com isso, o projeto desenvolvido pelo Instituto gera subsídios para as famílias, que têm como principal deles a pesca artesanal (INSTITUTO GOIO-EN, 2017a). 


\section{Considerações finais}

O objetivo deste estudo foi analisar as práticas de responsabilidade socioambiental adotadas pelo Instituto Goio-En para o desenvolvimento regional no seu âmbito de atuação. A partir das respostas obtidas nas entrevistas, foi possível identificar que o principal foco de atuação do Instituto, no momento, é a produção de alevinos para o repovoamento do rio e lagos da barragem Foz do Chapecó. Na execução de suas ações e projetos, o Instituto visa ao desenvolvimento regional.

A estação de piscicultura é tida como o principal foco de atuação. Estabelecida no município de Águas de Chapecó (SC), consiste em um amplo campo de pesquisa e produção de conhecimento e desenvolvimento. As atividades do Instituto e da estação são norteadas por princípios éticos de governança, com observância à legislação, uso de tecnologias limpas e observância aos princípios de sanidade animal, especialmente no que refere ao processo produtivo e à manutenção e conservação da estação.

Dada a dificuldade financeira do Instituto, ações e estratégias para a sustentabilidade financeira estão sendo reorganizadas. Essas ações incluem a ampliação do escopo de atuação e de captação de recursos, por meio de convênios, e a comercialização de alevinos. A atual situação econômica do Instituto decorre da redução de recursos captados por empresas parceiras, da redução da demanda dos demais serviços prestados pelo Instituto, a exemplo do plano diretor e plano de resíduos sólidos.

A gestão do Instituto é tida como transparente e participativa, sendo composta por conselhos constituídos por representantes da comunidade e de entidades parceiras, instituídos por participação democrática. O Instituto atua com princípios e diretrizes institucionais, objetivando a clareza dos processos e o bom relacionamento com os demais setores internos, instituições e funcionários.

Destacam-se a preocupação e a atuação voltadas para o desenvolvimento da comunidade na qual o Instituto está inserido, com vistas a orientar práticas de responsabilidade socioambiental, promovendo a preservação e a manutenção do ecossistema. Nesse sentido, a preservação dos recursos naturais é uma prática constante e difundida pelo Instituto. Contudo, a principal preocupação do Instituto no momento refere- 
se à sustentabilidade financeira, a qual se apresenta deficitária. Considerando que não há intenção em interromper as atividades desenvolvidas e que os principais princípios do Instituto são a autonomia e a sustentabilidade, a gestão, por meio de parcerias e convênios, ou da comercialização de alevinos, concentra esforços em estratégias que visam garantir a sustentabilidade.

No que diz respeito às limitações desta pesquisa, cabe mencionar dois aspectos principais. O primeiro baseia-se no fato de que as informações têm como fonte os relatos dos gestores e relatórios e notícias do próprio Instituto, as quais podem ter o viés do respondente para respostas socialmente desejáveis. Em um segundo momento, por tratarse apenas de uma organização, os achados devem ser considerados como circunscritos a apenas essa organização, não permitindo a generalização dos resultados. Recomenda-se para estudos futuros a adição de outras entidades dessa natureza, permitindo ampliar a análise realizada neste estudo, além de realizar estudos com a comunidade atendida, especialmente os ribeirinhos, para melhor conhecer as práticas sociais e ambientais desenvolvidas e os resultados obtidos.

\section{Referências}

ARAÚJO, E. T.; MELO, V. P.; SCHOMMER, P. C. O desafio da sustentabilidade financeira e suas implicações no papel social das organizações da sociedade civil. In: International Society for Third Sector Research, 2005.

ASHLEY, P. A. Ética e responsabilidade social nos negócios. São Paulo: Saraiva, 2003.

BARDIN, L. Análise de conteúdo. São Paulo: Edições 70, 2011.

BIER, F.; BASSAN, D. S. Responsabilidade social e ambiental: um estudo de caso em uma empresa de tecnologia em Porto Alegre. Colóquio, v. 12, n. 1, p. 149-164, 2015.

CALIXTO, L. Responsabilidade socioambiental: pública ou privada? Contabilidade Vista \& Revista, v. 19, n. 3, p. 123-147, 2008.

COSTA, M.; RAMOS, A.; PORTELA, S. A influência das organizações do terceiro setor na responsabilidade social e ambiental das empresas do polo industrial de Manaus. Revista Portuguesa e Brasileira de Gestão, v. 13, n. 1, p. 14-27, 2014. 
ELKINGTON, J. Sustentabilidade: canibais com garfo e faca. São Paulo: M. Books do Brasil, 2012.

Towards the sustainable corporation: win-win-win business strategies for sustainable development. California Management Review, v. 36, n. 2, p. 90-100, 1994.

FALCONER, A.P. A promessa do terceiro setor: um estudo sobre a construção do papel das organizações sem fins lucrativos e do seu campo de gestão. São Paulo: Centro de Estudos do Terceiro Setor da USP, 1999.

FERNANDES, R. C. O que é o terceiro setor? Revista do Legislativo, n. 18, p. 26-30, 1997.

FERNANDES, V. D. C.; VASCONCELOS; VALADÃO JÚNIOR. Gestão socioambiental em ONGs: um olhar a partir do desempenho empresarial e suas percepções como stakeholders de outras organizações. Revista Metropolitana de Sustentabilidade, v. 4, n. 2, p. 25-46, 2014.

FERNÁNDEZ, L. V.; JARA-BERTIN, M.; PINEAUR, F. V. Prácticas de responsabilidad social, reputación corporativa y desempeño financiero. Revista de Administração de Empresas, v. 55, n. 3, p. 329-344, 2015.

FISCHER, R. M. Estado, mercado e terceiro setor: uma análise conceitual das parcerias intersetoriais. Revista de Administração-RAUSP, v. 40, n. 1, p. 5-18, 2005.

FLICK, U. Introdução à pesquisa qualitativa. Porto Alegre: Artmed, 2009.

FOSTER, W.; BRADACH, J. Sem fins lucrativos, procure lucros. Harvard Business Review, v. 83, n. 2, p. 92-100, 2005.

FOZ DO CHAPECÓ ENERGIA SA. Repovoamento do Rio Uruguai. Disponível em:

<http://www.fozdochapeco.com.br/socioambiental/>. Acesso em: 29 set. 2017.

FUNDESTE. Balanço Social 2012. Disponível em:

<http://www.fundeste.edu.br/index.php/balanco_social_2012>. Acesso em: 10 set. 2017.

. Balanço Social 2014. Disponível em:

<http://www.fundeste.edu.br/index.php/balanco_social_2014>. Acesso em: 10 set. 2017.

Balanço Social 2015. Disponível em:

<http://www.fundeste.edu.br/index.php/balanco_social_2015>. Acesso em: 10 set. 2017.

Balanço Social 2016. Disponível em:

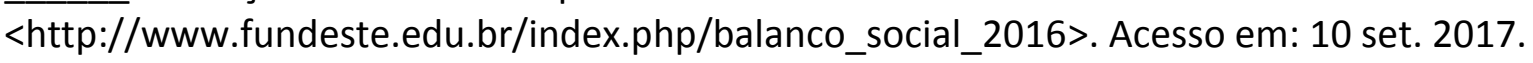

GEORGETA, G. A general framework of corporate social responsibility. Annals of the University of Oradea, Economic Science Series, v. 17, n. 2, p. 666-669, 2008. 
GIMENEZ, C.; SIERRA, V.; RODON, J. Sustainable operations: their impact on the triple bottom line. International Journal of Production Economics, v. 140, n. 1, p. 149-159, 2012.

HUBBARD, G. Measuring organizational performance: beyond the triple bottom line. Business Strategy and the Environment, v. 18, n. 3, p. 177-191, 2009.

INSTITUTO ETHOS. Indicadores Ethos para negócios sustentáveis e responsáveis: ciclo 2016/2017. Disponível em:

<https://www3.ethos.org.br/conteudo/indicadores /\#.WdbplmhSzIU>. Acesso em: 14 abr. 2017.

INSTITUTO GOIO-EN. Doação de peixes e repovoamento de rios. Disponível em:

<http://www.institutogoioen.org.br/index.php/desc_noticia/doacaeo_de_peixes_e_repovoa mento_de_rios/\#main_left>. Acesso em: 29 set. 2017a.

. Peixes nativos oportunizam o desenvolvimento da piscicultura regional. Disponível em: <http://www.institutogoioen.org.br/index.php/desc_noticia/peixes_nativos_oportunizam _o_desenvolvimento_da_piscicultura_regional/\#main_left>. Acesso em: 29 set. 2017b.

Regimento interno 2009. Disponível em:

<http://www.institutogoioen.org.br/index.php/institucional/\#main_left>. Acesso em: 2 out. 2017c.

JACOBI, P. Educação ambiental, cidadania e sustentabilidade. Cadernos de Pesquisa, v. 118, n. 3, p. 189-205, 2003.

JENTZ, G. J. et al. As dimensões da sustentabilidade em uma organização do terceiro setor em Santa Catarina: um estudo no programa oficina educativa Verde Vida. Amazônia, Organizações e Sustentabilidade, v. 4, n. 1, p. 127-150, 2015.

JUNQUEIRA, L. A. P. A gestão intersetorial das políticas sociais e o terceiro setor. Saúde e Sociedade, v. 13, n. 1, p. 25-36, 2004.

MAÑAS, A. V.; DE MEDEIROS, E. E. Terceiro setor: um estudo sobre a sua importância no processo de desenvolvimento socioeconômico. Perspectivas em Gestão \& Conhecimento, v. 2, n. 2, p. 15-29, 2012.

MCWILLIAMS, A.; SIEGEL, D. Corporate social responsibility: a theory of the firm perspective. Academy of Management Review, v. 26, n. 1, p. 117-127, 2001.

MCWILLIAMS, A.; SIEGEL, D. S.; WRIGHT, P. M. Corporate social responsibility: strategic implications. Journal of Management Studies, v. 43, n. 1, p. 1-18, 2006.

MURARO, P.; LIMA, J. E. S. Terceiro setor, qualidade ética e riqueza das organizações. Revista $F A E$, v. 6, n. 1, p. 79-88, 2003. 
OLIVEIRA, M. C. et al. Comunicação de responsabilidade socioambiental na missão, visão e valores de empresas da BM\&FBovespa e da Fortune 500. Contabilidade, Gestão e Governança, v. 19, n. 2, p. 192-210, 2016.

OLIVEIRA, L. R. et al. Sustentabilidade: da evolução dos conceitos à implementação como estratégia nas organizações. Production, v. 22, n. 1, p. 70-82, 2012.

PARENTE, T. C. et al. Gestão de mudanças nas organizações do terceiro setor: o desafio da sustentabilidade financeira. Gestão \& Regionalidade, v. 28, n. 84, p. 89-102, 2012.

PULLMAN, M. E.; MALONI, M. J.; CARTER, C. R. Food for thought: social versus environmental sustainability practices and performance outcomes. Journal of Supply Chain Management, v. 45, n. 4, p. 38-54, 2009.

RICO, E. M. A responsabilidade social empresarial e o Estado: uma aliança para o desenvolvimento sustentável. São Paulo em Perspectiva, v. 18, n. 4, p. 73-82, 2004.

RUSCHEINSKY, A. No conflito das interpretações: o enredo da sustentabilidade. Revista Eletrônica do Mestrado em Educação Ambiental, v. 10, p. 39-50, 2003.

SILVA, C. E. G. Gestão, legislação e fontes de recursos no terceiro setor brasileiro: uma perspectiva histórica. Revista de Administração Pública, v. 44, n. 6, p. 1301-1325, 2010.

SILVA, M. E.; COSTA, A. C. V.; GÓMEZ, C. R. P. Sustentabilidade no terceiro setor: o desafio de harmonizar as dimensões da sustentabilidade em uma ONG. Revista Reuna, v. 16, n. 3, p. 75-92, 2011.

SLAPER T. F.; HALL, T. J. The triple bottom line: what is it and how does it work? Indiana Business Review, v. 86, n. 1, 2011.

TILT, C. A. Corporate social responsibility research: the importance of context. International Journal of Corporate Social Responsibility, v. 1, n. 1, p. 2, 2016.

TRIVIÑOS, A. N. S. Introdução à pesquisa em ciências sociais: a pesquisa qualitativa em educação. São Paulo: Atlas, 2006.

VALADÃO JÚNIOR, V. M.; MALAQUIAS, R. F.; SOUSA, E. G. Controladoria como uma opção à sustentabilidade econômica nas organizações de terceiro setor: o caso de uma associação. Revista Contemporânea de Contabilidade, v. 5, n. 9, p. 131-151, 2008.

VAN AAKEN, D.; SPLITTER, V.; SEIDL, D. Why do corporate actors engage in pro-social behaviour? A Bourdieusian perspective on corporate social responsibility. Organization, v. 20, n. 3, p. 349-371, 2013. 
VEIGA-NETO, A. R.; PANHOSSI, K. R.; GODOY, A. F. M. Responsabilidade social em empresas privadas e sua relação com o terceiro setor. Revista Eletrônica de Administração, v. 10, n. 3, p. 1-18, 2004.

WORLD COMMISSION ON ENVIRONMENT AND DEVELOPMENT - WCED. Our Common Future. Oxford University Press, New York, 1987.

YIN, R. K. Estudo de caso: planejamento e métodos. Porto Alegre: Bookman, 2015.

ZHAO, L.; DU, J. Certification of environmental corporate social responsibility activities in differentiated duopoly market. Mathematical Problems in Engineering, v. 2017, p. 1-7, 2017. 